\title{
The relationship between social capital and mental health in individuals living with HIV in North of Iran
}

\author{
Fataneh Bakhshi ${ }^{1}$, Fatemeh Nezamdust ${ }^{2}$, Ehsan Kazemnejad Leili ${ }^{3}$ \\ ${ }^{1}$ Department of Health Education \& Promotion, Social Determinants of Health Research Center, School of Health, Guilan University \\ of Medical Sciences, Rasht, Iran \\ ${ }^{2}$ Master of Health Management, Rhino-Sinus, Ear, and Skull base Diseases Research, Center, Amiralmomenin Hospital, Guilan \\ University of Medical Sciences, Rasht, Iran \\ ${ }^{3}$ Social Determinants of Health Research Center, School of Nursing \& Midwifery, Guilan University of Medical Sciences, Rasht, Iran
}

\begin{abstract}
Introduction: Social capital, as one of the determinants of health, has a significant role on mental health of people especially chronic patients. This study aimed to investigate the relationship between mental health and social capital in HIV patients in North of Iran.

Material and methods: In this cross-sectional study, 49 persons with HIV referred to the consultation center of welfare organization in 2017 were included. Social capital of participants was measured by Bullen's social capital scale. Mental health questionnaire (GHQ-28) was used to determine the condition of mental health. Data were analyzed with SPSS 21 software. Pearson's correlation and regression analysis were applied to investigate the relation between variables.

Results: The mean score was $59.2 \pm 13.3$ for social capital and $31.4 \pm 12.2$ for mental health. There was a significant relationship between the total score of social capital with better economic condition $(p=0.01, r=0.33)$, lower duration of illness $(p=0.001, r=0.47)$, and having insurance $(p=0.007$, $r=0.38$ ). The correlation between variables showed a negative and significant relationship between dimensions of feeling of trust and safety $(r=-0.45, p=0.002)$, activity in a social context $(r=-0.41$, $p=0.004)$, and value of life $(r=-0.81, p=0.001)$ with mental health.

Conclusions: According to the study results, with increasing attention to health determinants and social capital as one of the international principles of health, mental health of people with AIDS should be promoted.
\end{abstract}

HIV AIDS Rev 2021; 20, 1: 33-38

DOI: https://doi.org/10.5114/hivar.2021.105110

Key words: social capital, mental health, HIV.

\section{Introduction}

Health is the most important component of social welfare; it is more dependent on social and economic factors than medical interventions and one of the central concepts of sustainable development. The amount of social capital and its different dimensions are important variables affecting the success of development, welfare, and social well-being programs [1]. Social capital is a set of norms in social systems that promotes the level of cooperation of its members, and
Address for correspondence: Fataneh Bakhshi, Department of Health Education \& Promotion, Social Determinants of Health Research Center, School of Health, Guilan University of Medical Sciences, 4146939814 Rasht, Iran, tel: +98-338-246-64, fax: +98-338-494-13, e-mail: sarisa808@gmail.com
Article history:

Received: 01.03.2020

Received in revised form: 24.08 .2020

Accepted: 26.08 .2020

Available online: 30.03 .2021
International Journal of HIV-Related Problems

HIV \& AIDS

R e vi e w 
reduces the level of exchange and communication costs [2]. This phenomenon, linked to social networking or public trust in evaluated individuals, has been linked to many studies on mental health [1]. The World Health Organization defines mental health as the ability to interact harmoniously with others, change and modify one's personal and social environment, resolve personal conflicts and desires logically, equitably, and appropriately, and believes that mental health is not simply lack of mental illness, but it is the power to respond to different kinds of life experiences flexibly and meaningfully [3]. In 2000, the American Psychiatric Association also introduced mental disorder as a disorder of psychological and behavioral manifestations of decreased performance that results in pain, discomfort, disability, and loss of individual independence [1]. Various research studies indicate the relatively high prevalence of mental health issues and disorders in our country, a major part of which is related to patients with chronic and incurable diseases. In this regard, social relationships that create emotional communication between individuals can give community members a greater sense of security and thus promote their mental health. The greater the social cohesion in the community, the healthier the community; and, on the other hand, reducing the burden of mental illness and promoting mental health increase the attributes needed to accept social roles of individuals [4]. Mental disorders can be seen in anyone, but these complications are far more common in AIDS patients, and currently, more than 33 million people are infected. There is ample evidence that these individuals' mental health is at greater risk than others. These include depression, suicide, and a tendency to drugs abuse. In this regard, it is useful for health professionals to understand the factors contributing to adaptation of this group to the complications and anxiety of this disease $[5,6]$. Mak et al. noted that the major issue for AIDS patients is their exclusion from society and discrimination in a way that affects their individual development, which is directly related to their mental health [7]. In a study, Lin et al. examined the levels of social capital on quality of life and mental health of AIDS patients in China, and found that poor social capital was significantly associated with reduced physical health and mental health disorders in those people [8].

Therefore, there is an urgent need for AIDS patients to receive psychiatric treatment and social support. The lack of adequate support in the community require basic and scientific action that can be implemented with their needs' assessment and prioritization. Determining relevant and affecting factors on mental health as well as social capital of these individuals can lead to future correct and preventive interventions, waste of time and cost, and specialized staff to eliminate health inequalities in this field. One of the indirect consequences of such actions is observing future preventive measures for these individuals, all of which would lead to an improved community health. The Guilan Welfare Organization had established a center for prevention and development, focusing on prevention of policy during renovation and structural transformations by providing various inter- ventions, such as setting up and expanding positive clubs and subsidizing psychological counseling to patients and their families. The organization supports job seekers work in reducing the prevalence and onset of social harm and risky behaviors. In addition to preventing AIDS by fundamentally modifying and promoting lifestyles, it also addresses a wide range of health problems. Therefore, the present study was conducted to help identify mental health and social capital of AIDS patients, and influencing factors among AIDS patients referred to the Behavioral Disease Counseling Center and the Positive Club.

\section{Material and methods}

This is a descriptive-analytical study, and the data were collected through a questionnaire. The statistical population of this study consisted of 49 patients living with AIDS referred to the Behavioral Disease Counseling Center and the Positive Club, with the supervision of Guilan Welfare Organization in northern Iran in 2017. About 60 patients from all over the province were covered by the Positive Club, out of which 49 met the inclusion criteria of the study.

\section{Inclusion criteria}

Literacy, no diagnosed psychological disorders, and ability to understand and answer questionnaire questions were the inclusion criteria. In this study, an available sampling method was used.

\section{Instruments}

All participants completed three questionnaires consisting demographic information, social capital, and mental health. The demographic questionnaire provided demographic information of the subjects (age, marital status, number of children, levels of education, economic status, and history of mental illness). In order to determine social capital, Bullen's standard social capital questionnaire with Cronbach's $\alpha$ reliability of 0.82 was used. The questionnaire included 36 questions in eight domains (participation in local community, feelings of trust and safety, proactivity in a social context, value of life, neighborhood connections, family and friends' connections, and tolerance of diversity). Questions in each domain were measured with a quadratic range from low to high, with scores ranging from zero to four. The sum of the scores determined the amount of social capital of an individual. A standard questionnaire of general health was used to determine mental health. The questionnaire was a self-report screening questionnaire, which was used to assess individual's mental health and screening for mental disorders, and included four scales of somatic symptoms, such as anxiety and sleep disorder, social dysfunction, and depression. Each scale contained 7 questions, and every question had a score from 1 to 4 , with a range of "no" to "more than usual". Higher scores in each domain and over- 
Table 1. Mean distribution of mental health and social capital domains among participants $(n=49)$

\begin{tabular}{|c|c|c|c|}
\hline Variable/Dimensions & Mean \pm SD & Minimum & Maximum \\
\hline \multicolumn{4}{|l|}{ Social capital } \\
\hline Participation in a local community & $11.3 \pm 3.0$ & 7 & 17 \\
\hline Feelings of trust and safety & $10.8 \pm 4.0$ & 5 & 17 \\
\hline Proactivity in a social context & $16.2 \pm 4.8$ & 7 & 27 \\
\hline Value of life & $3.3 \pm 1.8$ & 2 & 7 \\
\hline Neighborhood connections & $11.3 \pm 2.9$ & 5 & 15 \\
\hline Family and friends' connections & $6.6 \pm 1.8$ & 3 & 10 \\
\hline Tolerance of diversity & $4.3 \pm 1.8$ & 2 & 8 \\
\hline Overall social capital & $59.2 \pm 13.3$ & 31 & 77 \\
\hline \multicolumn{4}{|l|}{ Mental health } \\
\hline Somatic symptoms & $9.5 \pm 3.8$ & 4 & 15 \\
\hline Anxiety and insomnia & $6.9 \pm 5.8$ & 0 & 18 \\
\hline Social dysfunction & $7.1 \pm 3.6$ & 0 & 14 \\
\hline Depression symptoms & $8.1 \pm 6.3$ & 0 & 19 \\
\hline Overall mental health & $31.4 \pm 12.2$ & 11 & 55 \\
\hline
\end{tabular}

all indicated lower levels of mental health [9]. The results were statistically analyzed by SPSS software version 21 , and the relationship between variables was analyzed by logistic regression.

\section{Results}

The total of 49 patients were included in the study, 31 $(70.5 \%)$ of them were men. The mean age of the participants was $38.5 \pm 7.4$. Fifteen (30.6\%) were married, 29 (59.2\%) had no university education, and $69.4 \%$ had a moderate to poor economic status. $70.2 \%$ of the subjects were in the group with mental disorders, and among the four areas of mental health, the highest score belonged to the domain of physical symptoms $(9.5 \pm 3.8)$ and the lowest score was related to the domain of anxiety and insomnia symptoms ( $6.9 \pm 5.8)$. The mean score of social capital for the patients was 59.2 \pm 13.3 , and out of the seven domains of social capital, the highest score belonged to the domain of proactivity in a social context $(16.2 \pm 4.8)$ and the lowest score was related to the tolerance of diversity $(4.3 \pm 1.8)$ (Table 1$)$.

The research hypotheses were tested using two statistical techniques, including Pearson's correlation coefficient (for normal variables quantitative variables) and Spearman's correlation coefficient (for quantitative variables that did not follow normal distribution). During investigating the relationship between the domains of social capital and demographic characteristics of the participants, it was found that between the dimension of participation in a local community with insurance $(r=-0.41, p=0.04)$ and non-adherence to treatment $(r=-0.33, p=0.01)$, there was a significant and indirect relationship. Moreover, there was a correlation between feelings of trust and safety with mari- tal status $(r=-0.30, p=0.03)$, unemployment $(r=0.07$, $p<0.01)$, duration of illness $(r=0.39, p=0.006)$, having insurance $(r=0.31, p=0.02)$, and adherence to treatment $(r=-0.35, p=0.01)$. Also, there was a direct and significant correlation between the dimension of proactivity in a social context with better economic status $(r=0.62, p<0.001)$, insurance $(r=0.52, p<0.001)$, and non-compliance with treatment $(r=-0.52, p<0.001)$. The value of life was another dimension of social capital that was associated with freelance working or housekeeping $(r=0.35, p=0.04)$, better economic status $(r=0.8, p=0.01)$, and long duration of illness $(r=0.36, p=0.001)$ as well as insurance and adherence to treatment $(r=0.43, p=0.02)$ that were significantly and directly related. According to the findings of the present study, there was a direct and significant relationship between male gender $(r=-0.31, p=0.04)$ and higher economic status $(r=-0.47, p=0.001)$ with connection with neighbors. Better economic status $(r=0.40, p=0.04)$ and shorter disease duration $(r=0.33, p=0.023)$ had a direct and significant relationship with connection with family and friends. The difference between diversity tolerance and duration of disease $(r=-0.51, p=0.001)$ showed a significant and indirect relationship. There was a significant relationship between total social capital score with better economic status $(r=0.33$, $p=0.01)$, lower duration of illness $(r=0.47, p=0.001)$, and insurance $(r=0.38, p=0.05)$. Table 2 shows the relationship between the dimensions of social capital and mental health in the participants, and the correlation of total social capital score with direct mental health $(p=0.16)$.

In the present paper, logistic regression was used to evaluate mental health predictors using backward LR method. In Table 3, the results of duration of disease reduced the chance of mental health (higher than average score) $(\mathrm{OR}=0.618$; 
Table 2. Relationship between social capital and mental health dimensions of participants $(n=49)$

\begin{tabular}{|c|c|c|c|c|c|c|c|c|}
\hline Variable & $\begin{array}{c}\text { Participation } \\
\text { in a local } \\
\text { community }\end{array}$ & $\begin{array}{l}\text { Feelings } \\
\text { of trust } \\
\text { and safety }\end{array}$ & $\begin{array}{c}\text { Proactivity } \\
\text { in a social } \\
\text { context }\end{array}$ & $\begin{array}{l}\text { Value } \\
\text { of life }\end{array}$ & $\begin{array}{l}\text { Neighborhood } \\
\text { connections }\end{array}$ & $\begin{array}{l}\text { Family and } \\
\text { friends' } \\
\text { connections }\end{array}$ & $\begin{array}{l}\text { Tolerance } \\
\text { of diversity }\end{array}$ & $\begin{array}{l}\text { Total } \\
\text { social } \\
\text { capital }\end{array}$ \\
\hline \multicolumn{9}{|l|}{ Mental health } \\
\hline $\begin{array}{l}\text { Correlation } \\
\text { coefficient }\end{array}$ & -0.28 & -0.45 & -0.41 & -0.81 & -0.11 & -0.14 & 0.07 & 0.21 \\
\hline$p$-value & 0.060 & 0.002 & 0.004 & 0.001 & 0.45 & 0.34 & 0.63 & 0.16 \\
\hline
\end{tabular}

Table 3. Predictors of mental health in participants $(n=49)$

\begin{tabular}{|c|c|c|c|c|c|c|c|}
\hline \multirow{2}{*}{ Variable } & \multirow{2}{*}{ Beta } & \multirow{2}{*}{ S.E. } & \multirow{2}{*}{ Df } & \multirow{2}{*}{ P-value } & \multirow{2}{*}{ Odds ratio } & \multicolumn{2}{|c|}{$95 \% \mathrm{Cl}$} \\
\hline & & & & & & Lower & Upper \\
\hline Duration of illness & -0.48 & 0.153 & 1 & 0.002 & 0.618 & 0.458 & 0.835 \\
\hline Economic status & 2.48 & 0.770 & 1 & 0.001 & 11.989 & 2.649 & 54.267 \\
\hline Value of life & -4.21 & 2.058 & 1 & 0.041 & 0.015 & 0.001 & 0.837 \\
\hline
\end{tabular}

95\% CI: $0.458-0.835 \%$ ), and the higher the economic status score, the more the chance of mental health $(\mathrm{OR}=11.989$; 95\% CI: 2.649-54.267\%). Moreover, the value of life also decreased the chance of mental health $(\mathrm{OR}=0.015 ; 95 \% \mathrm{CI}$ : $0.0837 \%)$.

\section{Discussion}

Statistical analysis of the results of mental health variables showed that the studied patients had mild mental health problems in each dimension of physical symptoms, anxiety symptoms, social functioning, depression symptoms, and overall mental health score. Huang et al. in China also observed that about half of HIV-positive patients suffered from anxiety and depression symptoms [10]. Moreover, Tran et al. in a study from Vietnam reported mild to severe problems in examining different areas of mental health [11]. Dageid et al. observed that more than $78 \%$ of AIDS patients had a moderate or lower mental health score [12]. In Iran, a study comparing mental health in AIDS patients to those with hepatitis $C$, and revealed lower levels of mental health in AIDS patients [13]. Mostafa et al. also considered mental health of AIDS patients to be lower than others', due to the risk of their psychological approaches [14]. The mean social capital score in the present study was less than half of the full score. The comparison of this score with other studies examining social capital of individuals and groups showed that this value was much lower in the present study participants $[4,15]$. In a qualitative study, Rankin et al. reported a low-rate of utilization of social networks and, subsequently, a low-rate of social capital in patients with AIDS in Malawi [16]. Furthermore, Cuca et al. reported the average social capital of women with AIDS in San Francisco, USA [17]. The survey of each of the seven dimensions of social capital in our study showed that the scores obtained in participation in local community were lower than the mean and scores of other areas, and were equal to or slightly higher than the mean score. Similar studies in people with AIDS revealed that the amount of different dimensions of social capital in these patients was far below the rating of other research environments, and usually earned a score equal or below the average $[7,18,19]$. In their studies, researchers have found that high scores on different dimensions of social capital had an inverse relationship with the stigma associated with the disease and mental health status of AIDS patients $[17,20]$. Mukoswa et al. stated in their study that as social capital increased, treatment outcomes improved [21]. There was a significant relationship between the dimensions of trust and social security and activities in social fields with mental health. The results of other studies, which were in line with the findings of this study also showed that paying attention to the sense of security and trust as well as paving the way for increased engagement in social programs could increase social capital and improve symptoms by creating inter-social networks [22-24]. In the current study, marriage, having a job, having insurance, and adherence to treatment were the factors that had a positive effect on social capital. Other socioeconomic factors, such as being a woman and higher economic status, could have a direct impact on some aspects of social capital, including communication dimensions, and power of tolerance and value. In a similar study in India, Sivaram et al. found that adherence to treatment and association with AIDS were higher in women with AIDS than in men, which was consistent with the results of the current study [25]. Similarly, the results of a study by Cene et al. in the United States showed that having a job and health insurance would increase patients' social capital as increasing the adherence to AIDS [26]. Mukoswa also indicated that having a job would also increase the social capital of these patients [21]. In the present study, the economic status 
of the studied individuals had a direct relationship with their mental health status; therefore, the higher the score of their economic status, the better the chance of mental health increase. In most studies on social determinants of health, good and favorable economic status has been identified as a deterrent to diseases, such as AIDS, and in patients with better economic status, mental health would be significantly higher $[5,17,27,28]$. According to the results of the present study, the only predictor of mental health among AIDS patients in the province, among the various domains of social capital investigated, was the value of life. Jong et al. in their study found that women with AIDS who had a cell phone had a higher mental health by increasing their sense of self-esteem [24]. Findings of other study also showed that the value of life for AIDS patients led to reduced stigma and better health [17]. Among various predictors that have been identified in different studies on mental health, some of the studies have reached similar conclusions [29, 30]. According to the findings of our study, being married, having a job, having insurance, and adherence to treatment were the factors having facilitating or positive effects on social capital of the participants. On the other hand, increasing attention to social capital and dimensions, such as trust and social security as well as activities in social fields, could have a significant impact on mental health of the studied population. Proper social and financial support for these patients, helping to maintain their family relationships, and creating employment for them would have an important role in improving their mental health.

\section{Limitations}

The main limitation of this study was the low number of available samples. Because of the fear of stigma, people are reluctant to introduce themselves to government agencies.

\section{Acknowledgement}

The research team is grateful to the leadership and staff of the Guilan Welfare Organization for their support of the present study and its registration as a research project approved with No. 13292/94/734. The authors would also sincerely thank our dear patients who participated in this project.

\section{Conflict of interest}

The authors declare no potential conflicts of interest with respect to the research, authorship, and/or publication of this article.

\section{References}

1. Seyyedan F, Abdolsamadi M. The relation of social capital with mental health in women and men. Social Welfare Quarterly 2011; 11: 229-254.

2. Serageldin I, Grootaert C. Defining Social Capital: An Integrating View 1. Evaluation and Development. New York: Routledge; 2017. p. 201-217.
3. Halter MJ. Varcarolis' Foundations of Psychiatric-Mental Health Nursing. E-Book: A Clinical Approach. Elsevier Health Sciences; 2017.

4. Kamran F, Ershadi K. A survey on the relationship of intergraded social capital and mental health. Social Research 2009; 2: 29-54.

5. Yang JP, Leu J, Simoni JM, Chen WT, Shiu CS, Zhao H. "Please Don't Make Me Ask for Help": Implicit Social Support and Mental Health in Chinese Individuals Living with HIV. AIDS Behav 2015; 19: 1501-1509.

6. Nobakht A, Mohraz M, Rahimzadeh M, Tehranizadeh M, BehboodiMoghadam Z, Esmaelzadeh-Saeieh S. The effect of cognitive behavioural therapy on depression, anxiety, and stress in women with HIV. HIV AIDS Rev 2018; 17: 218-223.

7. Mak WW, Poon CY, Pun LY, Cheung SF. Meta-analysis of stigma and mental health. Soc Sci Med 2007; 65: 245-261.

8. Lin X, Lu R, Guo L, Liu B. Social capital and mental health in rural and urban China: a composite hypothesis approach. Int J Environ Res Public Health 2019; 16: 665.

9. Fathi Ashtiani A. Psychological tests (personality assessment and mental health). Tehran: Besat Press; 2008.

10. Huang X, Meyers $\mathrm{K}$, Liu X, et al. The double burdens of mental health among AIDS patients with fully successful immune restoration: a cross-sectional study of anxiety and depression in China. Front Psychiatry 2018; 9: 384.

11. Tran BX, Dang AK, Truong NT, et al. Depression and quality of life among patients living with HIV/AIDS in the era of universal treatment access in Vietnam. Int J Environ Res Public Health 2018; 15: 2888.

12. Dageid W, Grønlie AA. The associations between resilience, social capital and self-rated health among HIV-positive South Africans. J Health Psychol 2015; 20: 1463-1473.

13. Jani M, Jamilian H, Aramoon A. Comparing perceived stress, selfefficacy and mental health in patients with HIV and hepatitis C. Journal of Arak University of Medical Sciences 2017; 20: 12-21.

14. Mostafa MS, Ostovar Z, Danesh E. Comparing social problem solving ability and risk-taking behaviors in patients with AIDS and healthy individuals. Razi Journal of Medical Sciences 2017; 24: 1-8.

15. Bahadorikhosroshahi J, Hashemi Nosrat Abad T, Babapur Kheyroddin J. The relationship between social capital and psychological well-being among the students of Tabriz University. Social Cognition 2015; 3: 44-54 [In Persian].

16. Rankin SH, Jong S, Matovu S, Youmans S, Lindgren T. Sources of social capital for malawi people living with HIV. Glob Qual Nurs Res 2016; 3: 2333393616676432.

17. Cuca YP, Asher A, Okonsky J, Kaihura A, Dawson-Rose C, Webel A. HIV stigma and social capital in women living with HIV. J Assoc Nurs AIDS Care 2017; 28: 45-54.

18. Leung MR, Chin JJ, Petrescu-Prahova M. Involving immigrant religious organizations in HIV/AIDS prevention: the role of bonding and bridging social capital. Soc Sci Med 2016; 162: 201-209.

19. Pronyk PM, Harpham T, Busza J, et al. Can social capital be in tentionally generated? A randomized trial from rural South Africa. Soc Sci Med 2008; 67: 1559-1570.

20. Campbell C, Williams B, Gilgen D. Is social capital a useful conceptual tool for exploring community level influences on HIV infection? An exploratory case study from South Africa. AIDS Care 2002; 14: 41-54.

21. Mukoswa GM, Charalambous S, Nelson G. The association between social capital and HIV treatment outcomes in South Africa. PLoS One 2017; 12: e0184140.

22. Liu L, Pang R, Sun W, et al. Functional social support, psychological capital, and depressive and anxiety symptoms among people living with HIV/AIDS employed full-time. BMC Psychiatry 2013; 13: 324 .

23. Campbell C, Scott K, Nhamo M, et al. Social capital and HIV competent communities: the role of community groups in managing HIV/AIDS in rural Zimbabwe. AIDS Care 2013; 25 (Suppl 1): S114-S122. 
24. Jong S, Thompson L, Siril H, Urassa D. Social capital and networks and retention to HIV care among people living with HIV/AIDS (PLWH) in Tanzania. Ann Global Health 2016; 82: 391.

25. Sivaram S, Zelaya C, Srikrishnan A, et al. Associations between social capital and HIV stigma in Chennai, India: considerations for prevention intervention design. AIDS Educ Prev 2009; 21: 233-250.

26. Cené CW, Akers AY, Lloyd SW, Albritton T, Hammond WP, CorbieSmith G. Understanding social capital and HIV risk in rural African American communities. J Gen Intern Med 2011; 26: 737-744.

27. Lan GL, Yuan ZK, Clements-Nolle KD, et al. Social capital and quality of life among people living with HIV/AIDS in Southeast China. Asia Pac J Public Health 2016; 28: 325-335.

28. Webel AR, Sattar A, Schreiner N, Phillips JC. Social resources, health promotion behavior, and quality of life in adults living with HIV. Appl Nurs Res 2016; 30: 204-209.

29. Webel AR, Wantland D, Rose CD, et al. A cross-sectional relationship between social capital, self-compassion, and perceived HIV symptoms. J Pain Symptom Manag 2015; 50: 59-68.

30. Ferlander S. The importance of different forms of social capital for health. Acta Sociologica 2007; 50: 115-128. 